\title{
Swansea Bay Tidal Lagoon Annual Energy Estimation
}

\section{Sean Petley and George Aggidis ${ }^{1}$}

Lancaster University Renewable Energy Group and Fluid Machinery Group, Engineering Department, Lancaster University, Lancaster, Lancashire, LA1 4YR, UK.

\section{Highlights}

- OD modelling of Swansea Bay tidal lagoon for dual and ebb mode generation.

- Hydro turbine models with provision for sixteen $7 \mathrm{~m}$ diameter turbines.

- SeaZone bathymetric data manipulated using ArcGIS mapping.

- Dual mode approx. $480 \mathrm{GW}$ h per annum \& ebb mode increases annual energy gen. by $24 \%$

- Lagoon optimized ebb mode could improve generation by $50 \%$ compared to dual mode.

\section{Abstract}

UK Energy policy is focused on the challenges posed by energy security and climate change, however, efforts to develop a low-carbon economy have overlooked tidal energy a vast and unexploited worldwide resource. Since 1981, UK tidal lagoon schemes have been recommended as an economically and environmentally attractive alternative to tidal barrages. More recently, two proposals for tidal lagoons in Swansea Bay have emerged and there have been several reports documenting the potential to harness significant tidal energy from Swansea Bay using a tidal lagoon. This paper assists in determining a realistic approximation of the energy generation potential in Swansea Bay, a numerical estimation is obtained from a zero dimension, OD, 'backwards difference' computational model, utilising the latest turbine data available and high-resolution bathymetric data. This paper models the behaviour of the tidal lagoon in dual mode generation, in line with the above proposals. The results of model testing using a variety of fixed and variable parameters are displayed. The ebb mode model with provision for pumping at high tide is then explored further by carrying out

\footnotetext{
${ }^{1}$ Corresponding Author: George Aggidis

Telephone - +44 1524593052

Email-g.aggidis@lancaster.ac.uk
} 
optimisations of the starting head, number of turbines and turbine diameter in order to determine the maximum annual energy output from the tidal lagoon.

\section{Keywords}

1. tidal lagoon;

2. tidal modelling;

3. Swansea Bay;

4. tidal power;

5. turbines;

6. tidal range.

\section{$1 \quad$ Introduction}

Investigations into tidal power require some form of mathematical modelling that utilises a computer simulation of the water flowing in and out of estuaries. The data acquired from this can then be used to study and evaluate several aspects namely:

- The energy output of the tidal lagoon

- The effects of the lagoon on the water levels in the basin

- The effects of the lagoon on the seaward water levels

- Comparison of different methods of operating the lagoon

River or estuary flow can be simulated by DD, 1D, 2D or 3D modelling approaches, which increase in complexity. The 1D Saint-Venant equations, more commonly known as the shallow water equations model the response of an incompressible fluid to gravitational and rotational forces in open channel flow, providing average flow velocity and water elevation in each channel section (Randall, 2006). The shallow water equations also apply to a popular 2D modelling approach, in which they are derived by depth integrating the 3D Reynolds Average Navier Stokes equations from the river bed to the free surface (Falconer, Xi, Lin, \& Ahmadian, 2009). The 2D models consist of three equations; the conservation of the volume of water and two representing the conservation of water momentum, which depend on three hydrodynamic variables namely, water depth and the depth averaged velocity components in $x$ and $y$ directions (Bourban, Liddiard, Durand, Cheeseman, \& Baldock, 2013). Examples of 2D models include DIVAST from Cardiff University (Brammer, Falconer, Ellis, \& Ahmadian, 2014), which uses finite volume cell based numeric and SMARTtide from HR Wallingford, which uses finite element cell numeric (Bourban, Liddiard, Durand, Cheeseman, \& Baldock, 2013). 2D models assume a 
hydrostatic pressure distribution (Hervouet, 2007), however due to the need to model pressure terms, particularly on the upstream sides of the impoundment 3D models are usually applied in this nearfield zone. The governing equations are the 3D Navier Stokes with the Boussinesq approximation and the incompressible continuity equation. Though computational power has advanced in recent years, $3 \mathrm{D}$ modelling remains a complex task, therefore 3D models are usually coupled with 2D models in the far - field zones (Kilanehei, Naeeni, \& Namin, 2011).

An OD model provides a simplified approach to estimating the performance of tidal barrage or lagoon, the model is built on the assumption that a volume of water let into the lagoon will raise the level of the lagoon by an amount equal to the volume let in divided by the area of the lagoon at that moment in time (Aggidis \& Benzon, 2013). The model is constructed using MatLab with provisions for the user to vary the input parameters such as number of turbines, head height, turbine diameter, time period, etc. and return the potential power output.

In order to construct this model knowledge of the tides and bathymetric data for the bay is required. The behaviour of the tides is modelled in terms of an equation that includes the tidal constituents for Swansea Bay. The bathymetry of Swansea Bay is needed in order to determine the height of water within the lagoon. Together these form a vital part of the function of the model, namely that at any point in time the potential energy available from the enclosed body of water can be calculated (Aggidis, 2010). Tidal constituents are available from the United Kingdom Hydrographic Office (UKHO, 2013) and bathymetric data purchased for this research from SeaZone Ltd (Sea Zone Solutions, 2013). Turbine 'hill charts' for double regulated bulb turbines are used to calculate the flow and power output from a selected turbine at different flow rates and heads. Bulb turbines are employed widely across the world in low-head tidal power schemes, as they are one of the most efficient turbines for low head applications (Schneeberger, 2010). The double-regulated turbine 'hill chart' for this study uses new cutting edge turbine technology made available directly from Andritz Hydro (Aggidis \& Feather, 2012) A tidal lagoon is an offshore or partially offshore impoundment that unlike a tidal barrage does not block the estuary it occupies; the technology used is very similar to that found in hydropower schemes, however tidal currents are bi-directional.

Estimating the resource requires a number of assumptions: technical constrains of the device, device efficiency, and effect of resource extraction. Thus there is a large degree of uncertainty. One estimate suggest that the UK holds 50TWh/year, representing 48\% of the European resource (Hammons, 1993), and few sites worldwide are as close to electricity users and the transmission grid as those in the UK. 
In the 1980's the Department of Energy conducted a number of studies and it was concluded that there are 16 estuaries where tidal barrages should be capable of producing over 44TWh/year (Department of Energy, 1989). Tidal lagoon schemes in the UK originate from the 1981 Severn Barrage Committee headed by Sir Hermann Bondi (Sustainable Development Commission, 2007). The initial proposal was to dredge the Severn Estuary material against the coast creating bounded enclosures in shallow water only partially blocking the estuary, known as the Russell Lagoon, however these plans were abandoned. In 2004 a report backing the Swansea Bay lagoon was published by Friends of the Earth Wales, proposing this development as an environmentally and economically attractive alternative to the Severn Barrage (Friends of the Earth Cymru, 2004).

Swansea Bay is located in the Bristol Channel on the South Wales coastline, as part of the Severn Estuary it experiences one of the world's largest tidal ranges, often reaching 10m. In 2004 Tidal Electric Inc (TEL) announced proposals to build a $5 \mathrm{~km}^{2}$ tidal lagoon using twenty-four $2.5 \mathrm{MW}, 3.3 \mathrm{~m}$ diameter turbines. The W S Atkins report (WS Atkins, 2004) sponsored by TEL estimated costs in the region of f81.5 million (as of 2006), however this was met with scepticism and the Department of Trade and Industry anticipated the cost of the project to be $f 234$ million (Baker, 2006). More recently however, Tidal Lagoon Swansea Bay Plc (TLSB) have submitted a rival bid to develop a lagoon in Swansea Bay, the outline of which is shown in Figure 1. TLSB are suggesting a much larger $11.5 \mathrm{~km}^{2}$ structure with sixteen $20 \mathrm{MW}, 7 \mathrm{~m}$ diameter turbines capable of generating $495 \mathrm{GWh} /$ annum (Case, 2014). Independent consultants Pöyry estimate the capital costs of the TLSB lagoon to be $f 913$ million (Poyry Consultants, 2014). Both companies plan to operate on a dual mode generation.

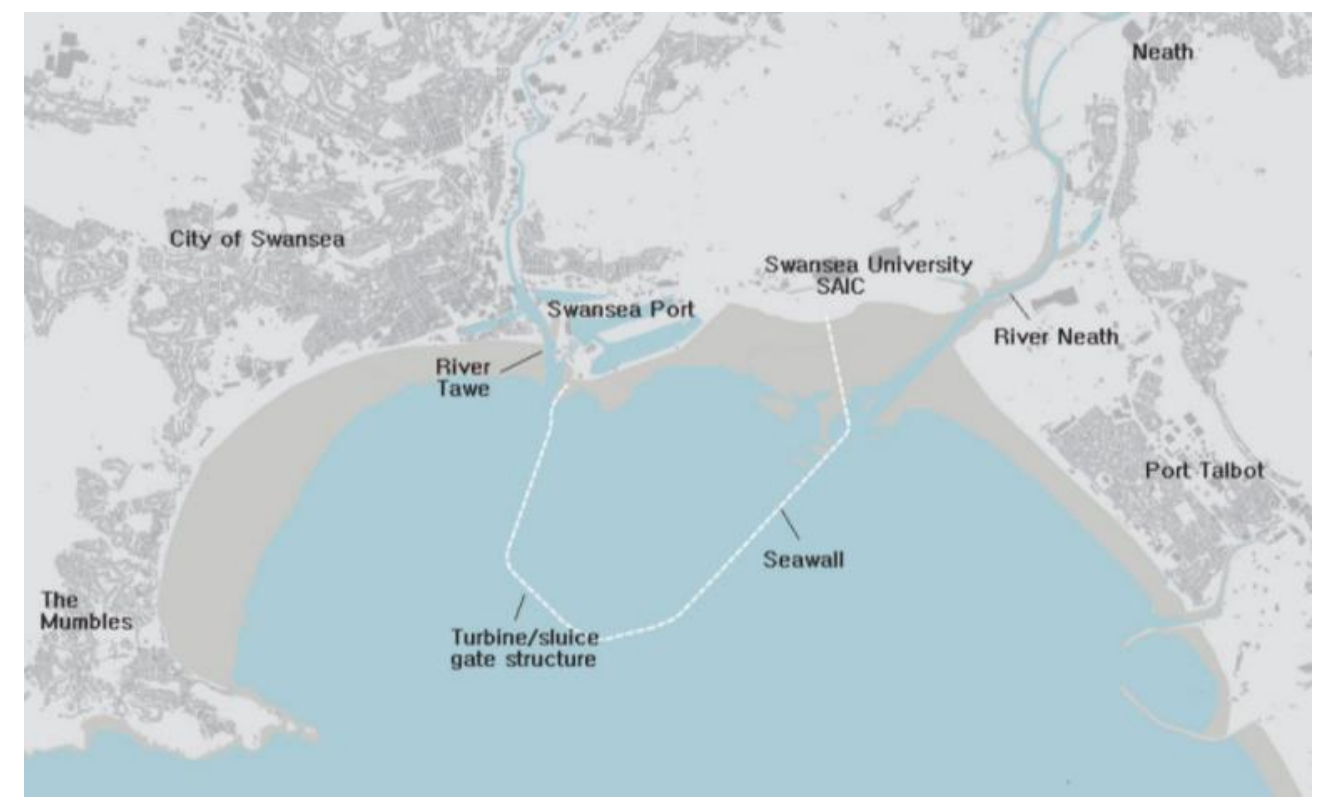

Figure 1: Map showing proposed layout of tidal lagoons in Swansea Bay (Case, 2014) 
The Swansea Bay tidal lagoon schemes demonstrate a renewed interest in tidal power, which has long been seen as having significant potential and has many advantages compared to other renewable sources. It is well documented that increasing integration of volatile, unpredictable sources of renewable energy such as wind power and solar power jeopardises the stability of the power grid (Krenn, Helmut, \& Sallaberger, 2013). In order for the grid to remain stable the power generated at any instance has to match demand, therefore it is important that the transmission network contains power sources that are immediately available. Tidal power has an obvious advantage in that the tidal resource is highly predictable such that it is known when power will be made available and enables National Grid forecasting. In an effort to decarbonise the UK energy mix, tidal power could potentially play a crucial role in maintaining the security of energy supply under UK national control.

\section{$2 \quad$ Tidal Lagoon Computational Model}

The dual mode model employed in this study uses both the flood and ebb phases of the tide to generate electricity. The flood tide is restricted from flowing though the sluices and turbines allowing a substantial head to build up on the tide side. After this point the sluices are opened enabling water to flow through the turbines, generating electricity. At high tide, the sluice gates are closed and the water is trapped behind the barrage and water on the sea facing side is allowed to ebb. When a significant head difference is achieved the water in the lagoon is then allowed to flow through the turbines to generate in the ebb mode.

Investigations into the component parts required to develop the OD model are documented in the following sub-sections.

\subsection{Bathymetry}

Bathymetric data is an integral part of the tidal lagoon model and is used to calculate the variation in depth of Swansea Bay as the tide ebbs and floods into the bay. The data was provided by SeaZone Limited as Survey Depth Soundings in ASCII XYZ Format, which was imported into ArcGIS in Global Latitude-Longitude format and then displayed as XY data. With the data imported into ArcGIS the first step was to create a Triangular Irregular Network (TIN); a digital means to represent surface morphology. TINs are a form of vector-based digital geographic data and are constructed by triangulating the bathymetric vertices. There are different methods of interpolation to form these 
triangles, however ArcGIS supports the Delaunay triangulation method. The TIN was created and colour scaled accordingly.

Once the TIN had been created the next step was to create a flat water surface over the bay area. At this stage it was assumed that the bay would fill up in stages defined by a number of layers from the sea floor to the highest water level - whilst this is not how the tides flood the bay it is a valid assumption to make for the OD model used in this study.

It was also assumed that water flows into the bay from the sea to the shore, this was achieved by making a number of transects across the bay from South to North as shown in Figure 2, the XZ data for each transect was exported to MatLab to generate a surface profile graph showing the variation with depth along the $\mathrm{X}$ axis or bay width. A total of 8 transects were taken.

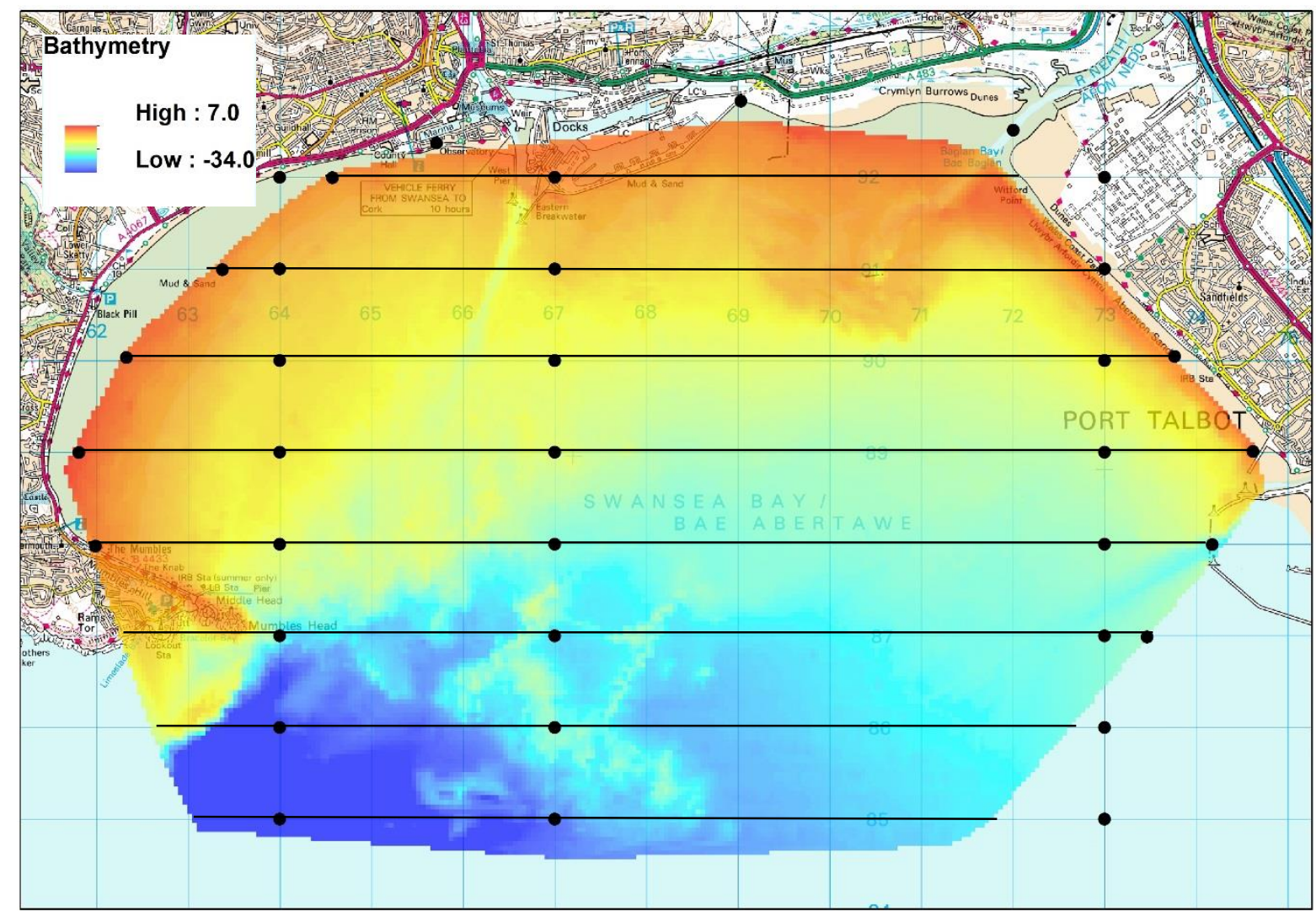

Figure 2: Chart showing the 8 transects and the mean nodal points across Swansea Bay (key in meters)

An Inverse Distance Weighting (IDW) function was then used to interpolate a surface, which follows the mean depth nodal points, as shown in Figure 2. The IDW surface was created to follow the gradient of the bay, imagining how the water would fill the surface over time. The IDW surface created is 
illustrated in Figure 3 below with a colour scaling to show the change in depth along the surface of the bay.

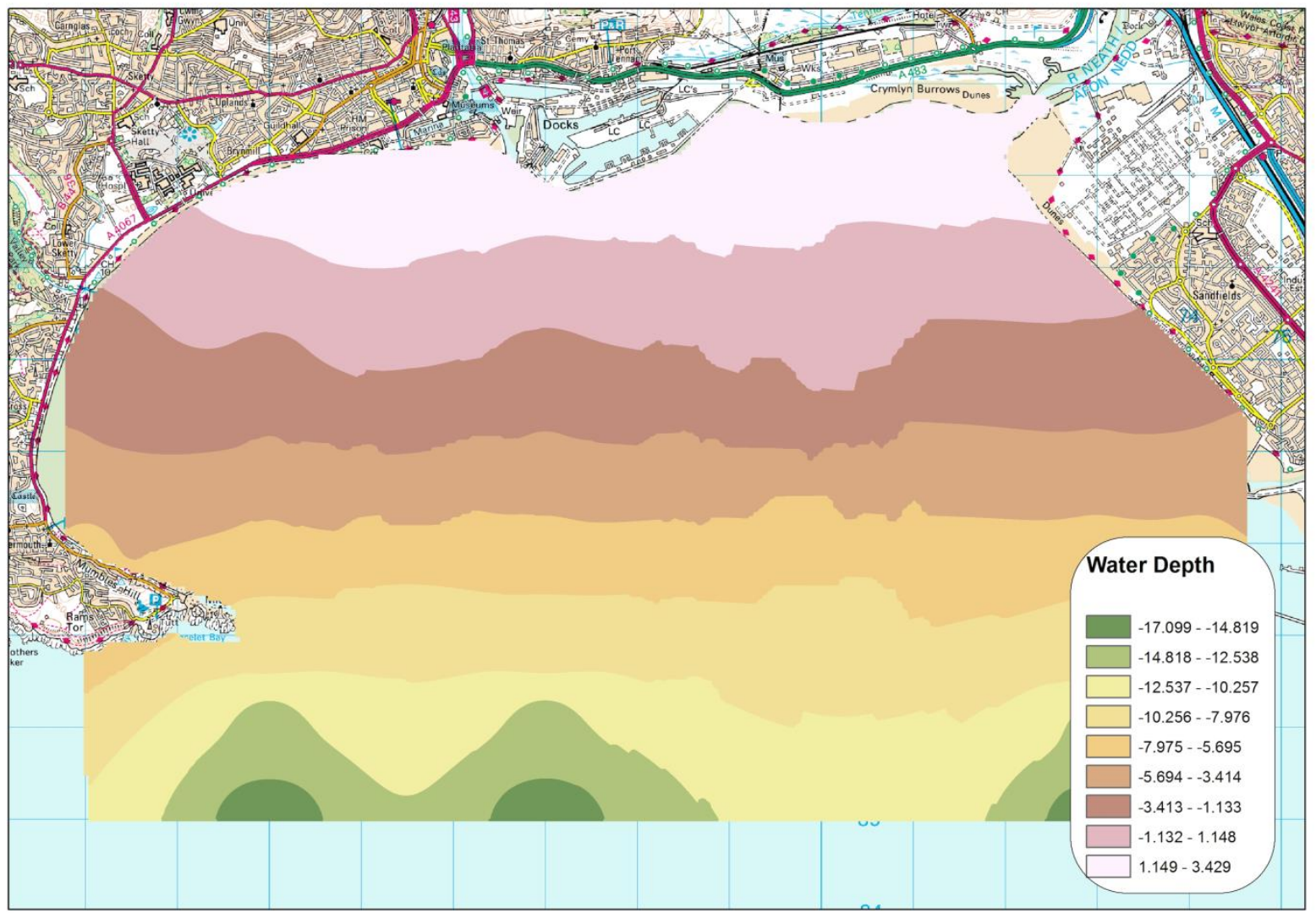

Figure 3: First IDW surface at Mean Sea Level (key in meters)

The first IDW surface was created at Mean Sea Level (MSL) measured from the Ordinance Datum Newyln, however in order to calculate the enclosed volume of water in the lagoon over a range of depths a number of IDW surfaces were created at varying heights about the MSL. The created surfaces accurately simulate the variation in water level at various depths during the tidal cycle, the IDW surfaces were created between MSL+5 and MSL-3 at $1 \mathrm{~m}$ intervals. The 'Mask' tool was then used to define the outline of the lagoon area, this ensured that processing only occurred on locations that fall within the mask, and that all locations outside of it were assigned to 'No Data' in the output as desired. The mask outline is shown in Figure 4. The final stage of the bathymetric calculations in ArcGIS was to calculate the volume and surface area of submerged water within the lagoon area for each of the 9 IDW surfaces, for this task the Cut/Fill tool was used. The Cut/Fill tool enables the user to create a map based on two input surfaces displaying the areas and volumes of surface materials that have been modified by the removal or addition of surface material (ESRI, 2013); this is illustrated in Figure 5. 


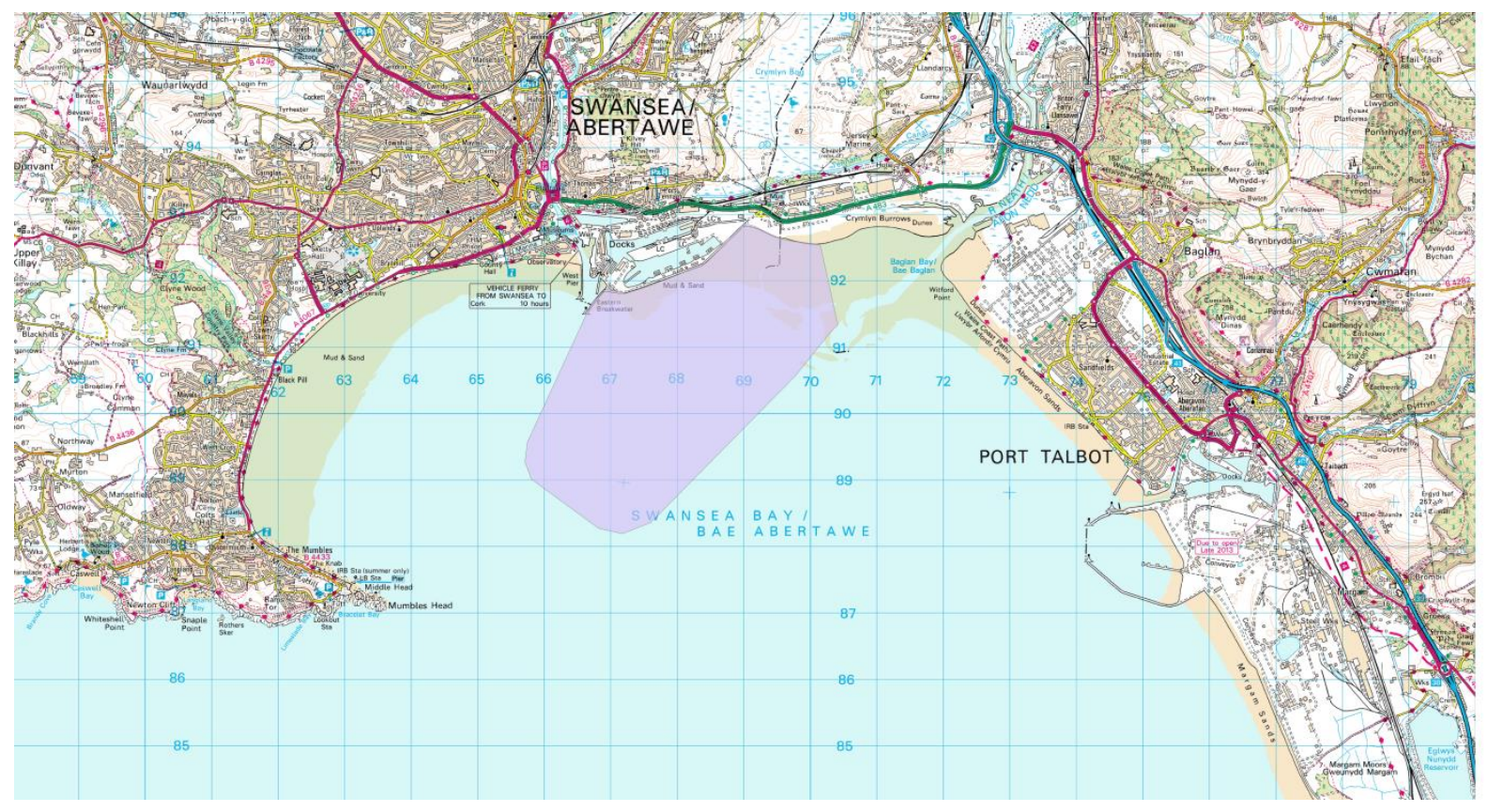

Figure 4: Swansea Bay Lagoon Mask

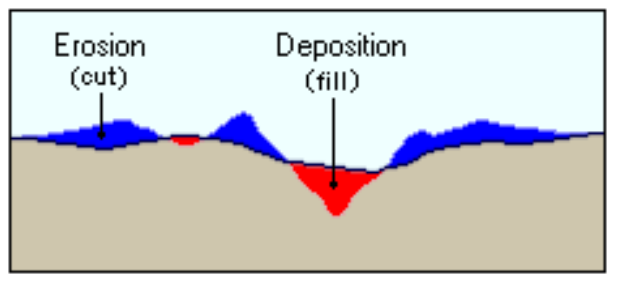

Figure 5: Cut/Fill function, showing removed (cut) and added (fill) material (ESRI, 2013)

Using the TIN and the IDW for each surface, the Cut/Fill function calculates the volume of landmass and its corresponding surface area above and below the plane that will be filled during the tidal cycle and sums the individual volumes and areas. For the purposes of bathymetric calculations the deposition volumes and areas will be considered.

The plotted depth/volume curve is shown in Figure 6 generating a line of best-fit curve. MatLab was used to calculate by least-squares the polynomial curves. Equations $(1 \mathrm{~A})$ and $(1 \mathrm{~B})$ show the obtained expression for the depth/volume curve from the MatLab calculation for $Z<0$ and $Z>=0$ respectively. 


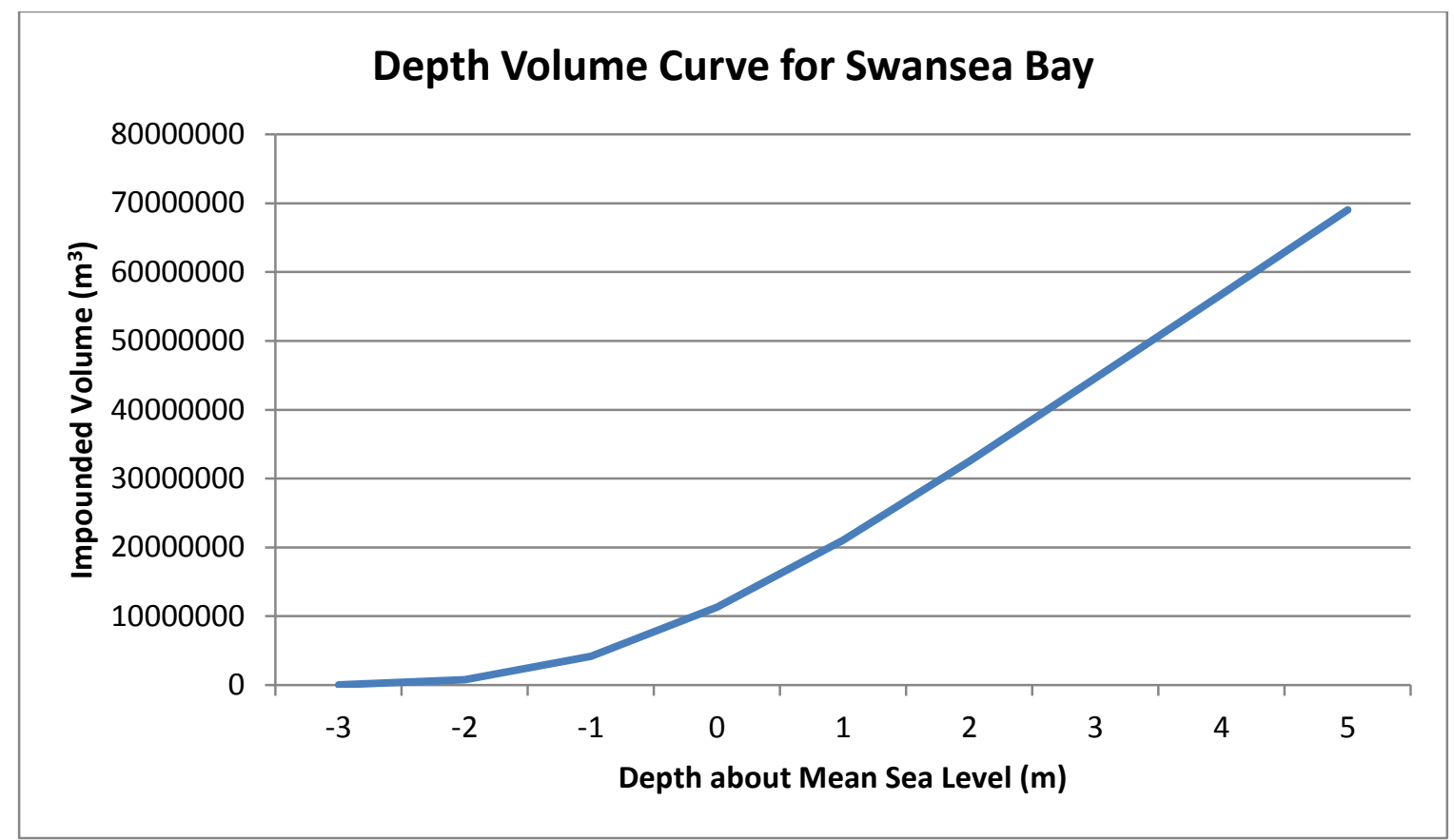

Figure 6: Depth Volume Curve

For $Z<0$

$$
V=0.1285 \times 10^{7} Z^{2}+0.7212 \times 10^{7} Z+1.0085 \times 10^{7}
$$

And for $Z>=0$

$$
V=-0.0113 \times 10^{7} Z^{3}+0.1144 \times 10^{7} Z^{2}+0.8617 \times 10^{7} Z+1.1458 \times 10^{7}
$$

\subsection{Calculation of the Tidal Height about Mean Sea Level}

Tides can be considered by observing the tidal constituents, where mean spring tides can be expressed as the sum of amplitudes (M2+S2) and mean neap tides (M2-S2) where M2 is the moon's principal twice-daily constituent and S2 is the sun's. Fourier analysis shows that any function can be broken down to its sine and cosine constituents; therefore any sinusoidal tidal variation can be broken down into the sum of a series of sinusoids (referred to as tidal constituents). Each tidal constituent will have a period of oscillation based on the celestial forcing which gives rise to it (VIMS, 2013). Each constituent is a sine wave whose height at any time is defined by a modified version of the simple relationship:

$$
Y(t)=H \cos (\omega t-\phi)
$$


Where $H$ is the amplitude, $\omega$ is the speed of rotation, $t$ is the time elapsed since the selected starting point and $\phi$ is the phase lag.

A database for tidal constituents is maintained and updated by the United Kingdom Hydrographic Office (UKHO, 2013), the constituents for Swansea Bay are given in Table 1:

\begin{tabular}{|c|c|c|c|c|}
\hline Constituent & $\begin{array}{c}\text { Constituent amplitude, } \\
\mathbf{H}(\mathbf{m}) \text { ATT (2012) }\end{array}$ & $\begin{array}{c}\text { Degrees per } \\
\text { hour }\end{array}$ & $\begin{array}{c}\text { Radians per hour } \\
\mathbf{( \omega )}\end{array}$ & Phase degree \\
\hline $\mathrm{M}_{2}$ & 3.18 & 28.984 & 0.5058 & 173 \\
\hline $\mathrm{S}_{2}$ & 1.13 & 30.000 & 0.5236 & 220 \\
\hline $\mathrm{K}_{1}$ & 0.07 & 15.041 & 0.2625 & 128 \\
\hline $\mathrm{O}_{1}$ & 0.07 & 13.943 & 0.2434 & 356 \\
\hline
\end{tabular}

Table 1: Tidal Constituents for Swansea Bay

The equation (4) below was used to plot the UKHO tidal curve using tidal constituents as an expansion of equation (3), to include all four tidal constituents.

$$
\begin{gathered}
Y(t)=3.18 \cos (0.5058 t-3.019)+1.13 \cos (0.5236 t-3.84)+0.07 \cos (0.2625 t-2.23) \\
+0.07 \cos (0.2434 t-6.21)
\end{gathered}
$$

It is necessary to point out that the tides cannot be fully expressed by using only four tidal constituents, however previous research has used four constituents and the results of these studies are considered to be suitably accurate. BODC have a station at Mumbles Head in Swansea Bay that measures the observed sea level therefore it is possible to calculate the difference between the observed and predicted sea level, also known as the residual value. To demonstrate the accuracy of the tidal constituent method the residual values have been plotted against the number of times it occurs over one month (September 2012), as shown in Figure 7. The mean value for the residual value is $0.01 \mathrm{~m}$. 


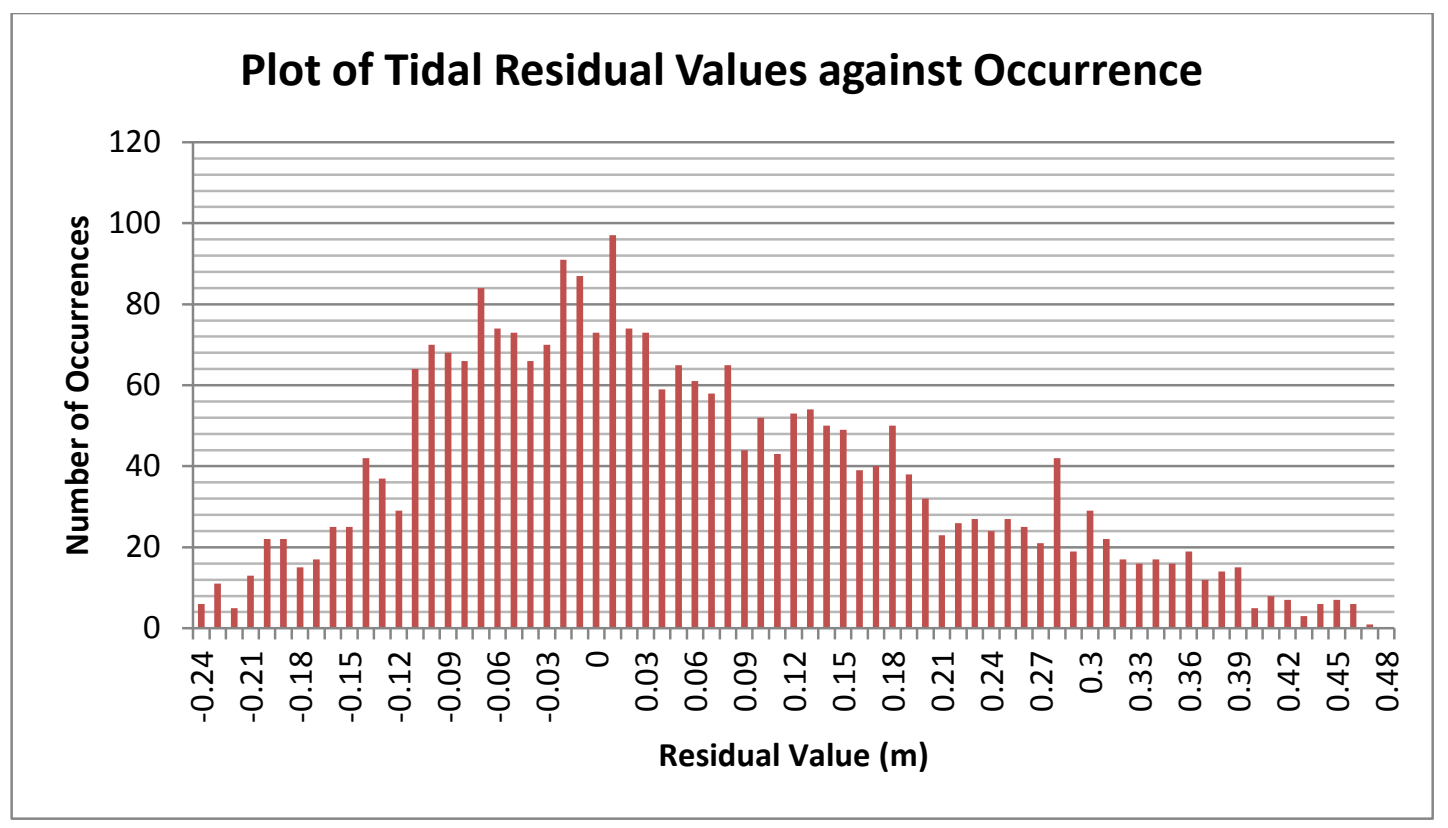

Figure 7: Tidal Residuals at Mumbles Head

\subsection{Lagoon Computational Model}

The OD model was created in MatLab and follows the approach of previous research. The generation stages combine the calculation for turbine flow rate with the lagoon depth/area calculations to give the flow at regular intervals based on the head of water at that time. The backwards difference approach uses the flow through the turbines over a defined time period, $0.1 \mathrm{~h}$, to find the new volume of water in the lagoon by deducting it from, in the case of flood mode, and adding it to, in the case of ebb mode the volume of water at the beginning of the $0.1 \mathrm{~h}$ interval.

Using Prandle (Prandle, 1984), the lagoon depth is calculated and compared to that at the start of the interval. As the tidal height at any point in time is known from the tidal equation (4), the difference between the lagoon water level, $Z(t)$ and the height of the tide $Y(t)$ at that particular moment gives the head, $H$, of water.

The operation of the tidal lagoon as implemented in the creation of the MatLab model can be broken down into four distinct stages for dual mode generation, shown in Figure 8. The governing equations of the separate stages have been defined using logic, the following sub-sections detail the calculations taking place at each stage. 

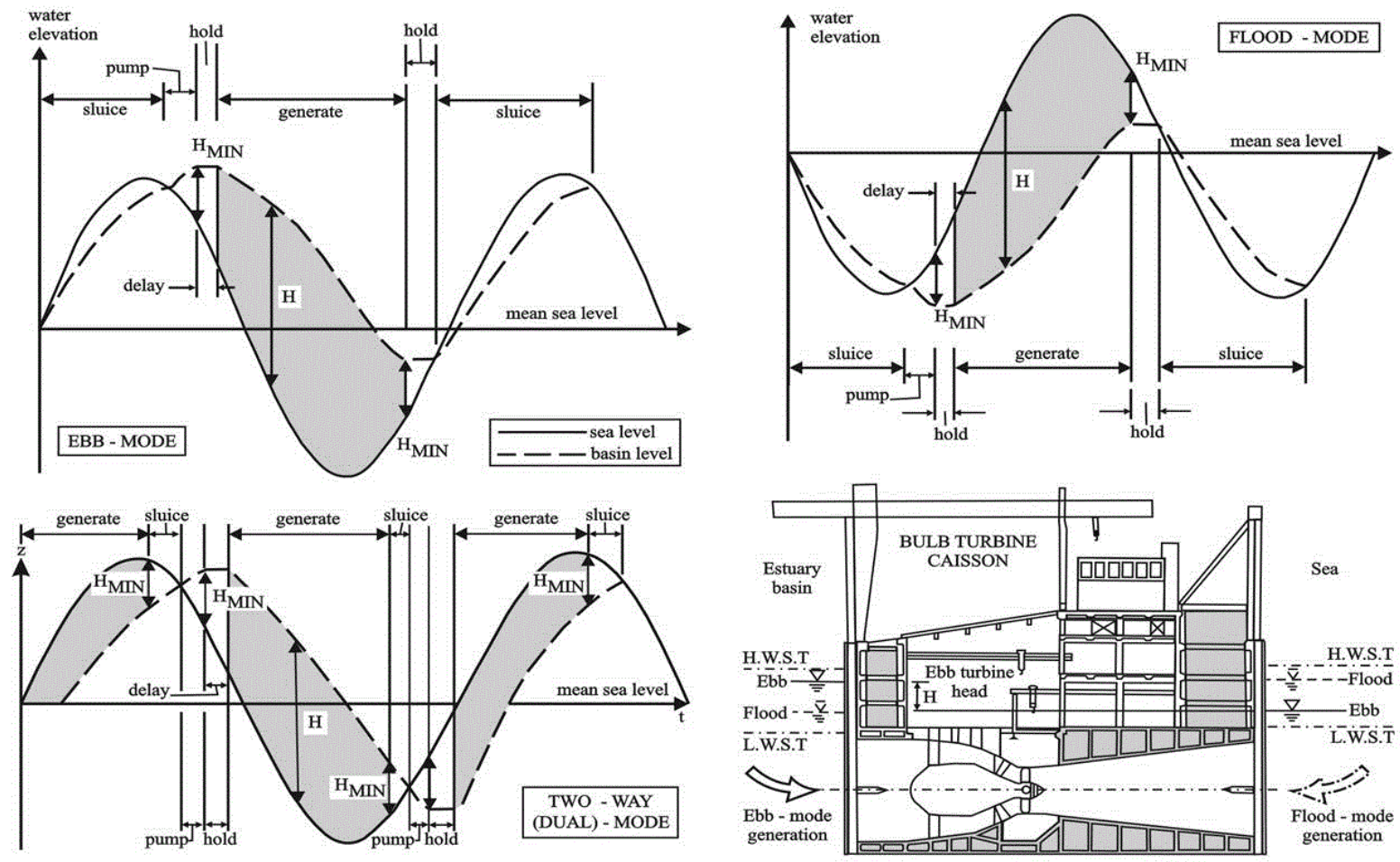

Figure 8: Outline of different operating modes (Burrows, et al., 2009)

\section{3 .1 \\ Hold Period}

The flat sections of the lagoon curve, where no generation occurs, indicate the hold period. There are two distinct hold stages, one for ebb mode and one for flood mode generation, both are defined by the minimum turbine generating head typically between $1-2 \mathrm{~m}$ depending on manufacturer. When the difference between sea and lagoon water level reaches the minimum head, generation can begin. For ebb mode this condition is defined as $Z(t)-Y(t)<S$, for flood mode $Y(t)-Z(t)<S$.

\subsection{2 \\ Lagoon Filling}

In dual mode, generation occurs during the filling stage forming the flood mode phase of the cycle. Generation phases combine the bathymetry calculations found in section 2.1 with the bulb turbine hill chart equations. The hill chart used in this model is shown in Figure 9 and was supplied by Andritz Hydro. 
Over a single time interval the following takes place:

1. The unit speed, $n_{11}$ is calculated from $H$, the synchronous speed $S p$ and the turbine diameter, $D$, from equation (5), the corresponding unit discharge $Q_{11}$ is found from the maximum output curve of the hill chart, the equation of which is defined in (Aggidis \& Feather, 2012).

$$
n_{11}=\frac{S p \times D}{\sqrt{H}}
$$

2. The vertical axis of the hill chart defines the unit discharge as equation (6), which can be rearranged to find flow rate $Q$. The total flow rate can be found by multiplying $Q$ by the number of turbines $N$.

$$
Q_{11}=\frac{Q}{\sqrt{H} \times D^{2}}
$$

3. From the initial value of the water level $Z$, the volume of water in the lagoon can be calculated using equation (1), the new volume of water in the lagoon can be calculated by the addition of the flow rate $Q$ from (5), and by dividing this by the surface area occupied the new lagoon water level $Z$ is found.

4. The head $H$ and the turbine efficiency curve and combination of hydraulic, generator and powertrain efficiency from (Aggidis \& Benzon, 2013) can be used to calculate power $P$ per turbine from equation (7).

$$
P=\rho \times g \times Q \times H \times \eta
$$

5. The power per turbine is multiplied by $N$ to give the total power, which is multiplied by the time per interval, $0.1 \mathrm{~h}$, to give the energy per interval. This can be summed over several intervals to give an overall energy production for the time period, as desired.

The maximum operating line defined on the hill chart can be split into two sections, the gradient represents the maximum allowable opening of the turbine distributor and runner blades for acceptable operation, and is therefore maximum flow. The horizontal section represents the maximum product of head, flow and efficiency, above this line the increase in flow is offset by the reduction in efficiency. At lower specific speeds the power generated by these flow rates has exceeded the generator limit, therefore the flow rate needs to be sufficiently reduced. The model accounts for this and reduces the flow in the most efficient manner. 
The flood mode generation phase holds true only when the following conditions are met, namely $Y(t)-Z(t)>S$, where $S$ is the minimum head. The program would run through the generation cycle whilst these conditions are met until the head reaches a minimum at which point the hold phase begins.

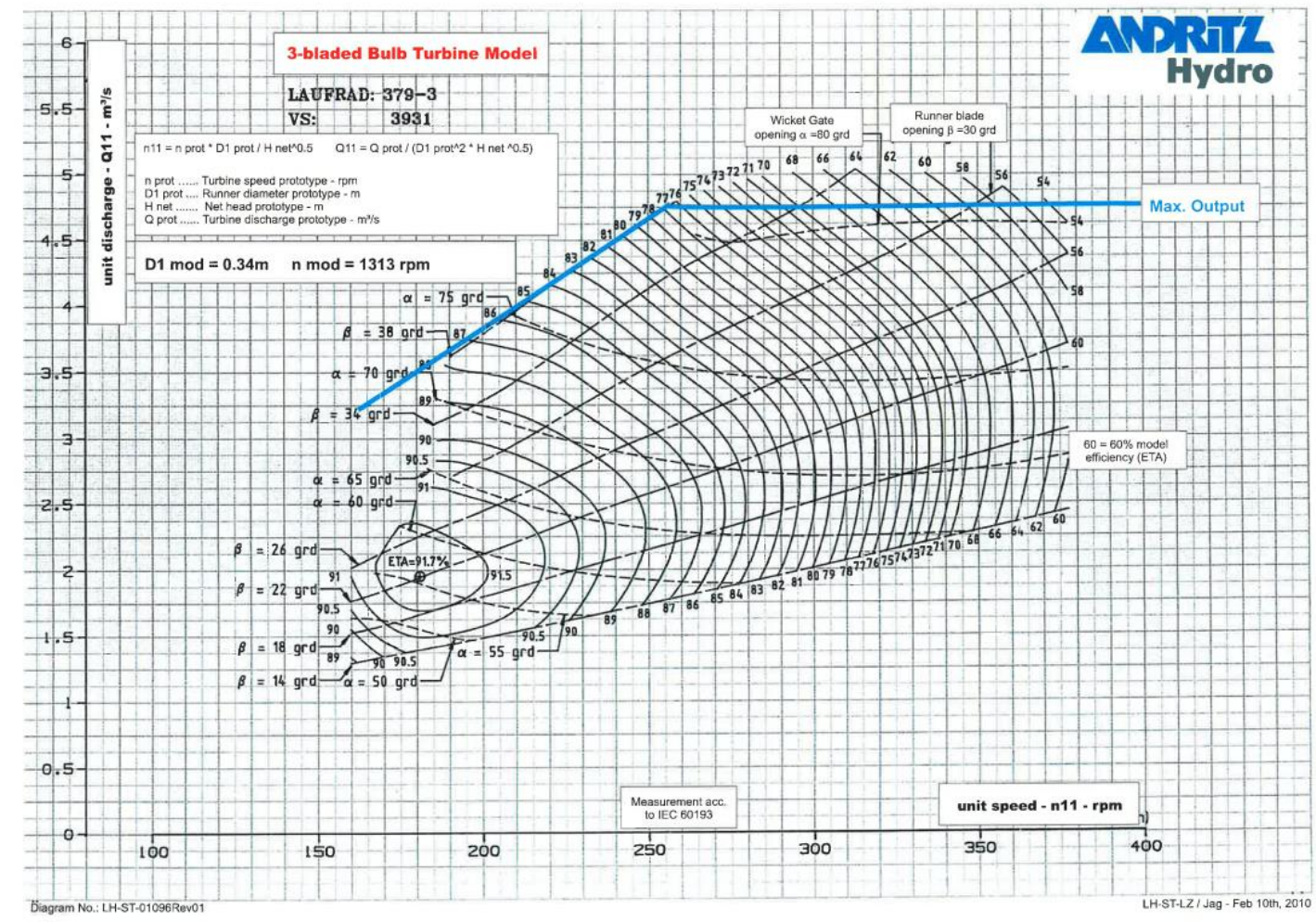

Figure 9: Andritz Hydro Hill Chart

\subsubsection{Lagoon Emptying}

In dual mode, generation also occurs during the emptying stage forming the ebb mode generation phase of the cycle. The procedure for calculating the generation phase is the same as lagoon filling, however only when the following conditions are met, namely $Z(t)-Y(t)>S$.

\section{$3 \quad$ Results and Discussion}

\subsection{Dual Mode Results}

The dual mode model results were calculated based upon the input parameters that follow the design selection made by TLSB, namely:

Diameter $-D: 7 \mathrm{~m}$; 
Number of Turbines $-N=16$;

Generator Capacity - Pmax $=16 * 20 \mathrm{MW}=320 \mathrm{MW}$;

Time - 365 days;

Minimum generating Head $-S=1 \mathrm{~m}$.

The total energy generated for the time period was calculated to be $479.8 \mathrm{GWh}$, which is very close to the published annual energy estimation of $495 \mathrm{GWh}$. Figure 10 shows the results of the model simulation for a 14 day time period, it shows 3 subplots generated by the OD model using the parameters listed above. The top subplot shows the variation in sea level (green) and variation in lagoon water level (red) during the 14 day tidal cycle. The middle subplot shows the power output by the water flowing through the turbines, and the bottom subplot shows the rate of discharge.
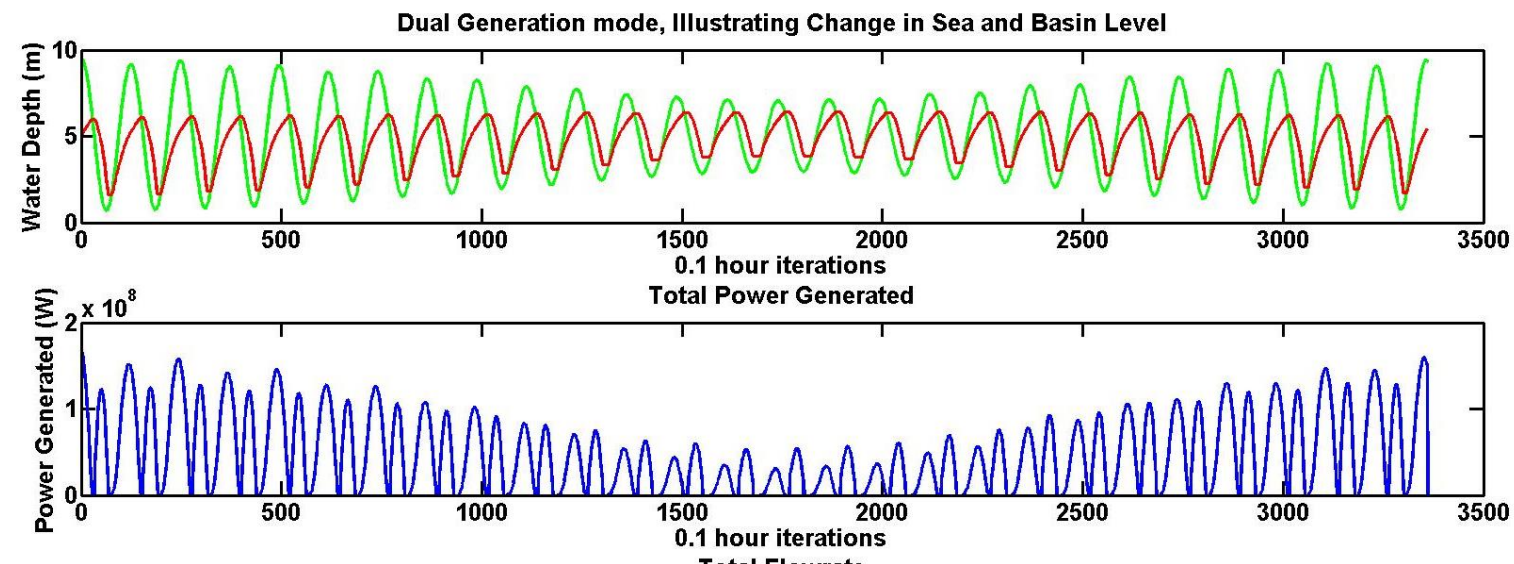
Total Flowrate

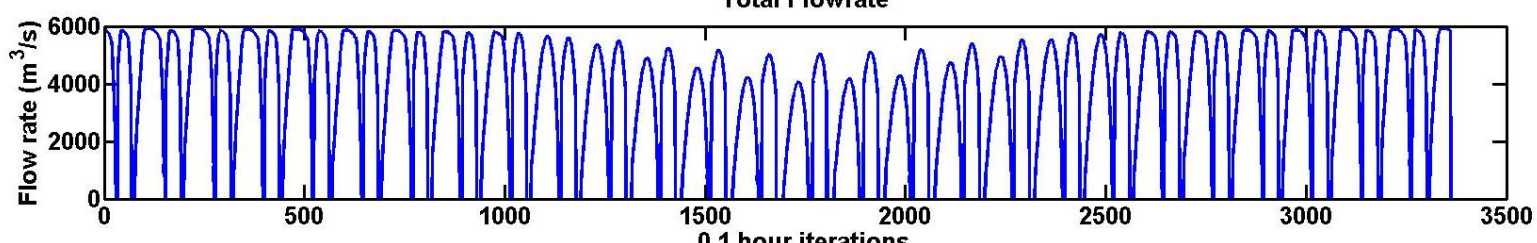

Figure 10: Dual Mode Generation 3 subplots

Figure 10 gives an indicative example of the expected power generation, showing a maximum of 160 $\mathrm{MW}$, despite this being half the installed capacity of the plant, indicating that the parameters chosen have not been optimised. In addition it has been documented in previous studies that dual mode generation offers a lower annual energy production when compared to just ebb mode generation. Burrows noticed in simulation studies of the Dee Barrage that dual mode operation is 'typically found to yield energy in the range of $78-98 \%$ of that achieved from the equivalent ebb mode', this can be explained as a result of several reasons. Firstly, the ebb mode sequence starts at a basin level which is much lower than for ebb mode generation alone, towards the end of the ebb generating 
sequence sluices are used to reduce the basin to a minimum level sufficient for the flood generation phase, essentially wasting generating capacity. Secondly, it is the combination of lower heads during each phase compared with one way generation and the fact that there is an associated efficiency 'cost penalty' on the basis of running the turbines in reverse during flood generation phase that results in dual mode not producing more energy that one way generation, this prompted the authors to investigate ebb mode generation.

\subsection{Ebb Mode Generation Results}

In ebb mode no generation takes place during the lagoon filling stage, therefore the code must account for the water that enters the lagoon through the sluice gates and the turbines acting in sluice mode. Equation (8) defines the flow rate through an opening in relation to the height of fluid above the opening and because the turbines are assumed to be fully submerged the equation may also be used for turbines acting in sluice mode.

$$
Q=A_{S} \times C_{d} \times \sqrt{2 \times g \times H}
$$

Where $Q$ is the discharge measured in $\mathrm{m}^{3}$, the coefficient of discharge $C_{d}$ assumed to be 0.9 , and the area of opening, $A_{S}$.

The dual mode OD study used the parameters selected by TLSB to offer a direct comparison to the scheme and initially the ebb mode study was similarly computed with thirty $15 \mathrm{~m} \times 10 \mathrm{~m}$ sluice gates. The area of opening can be taken as the combined area of the sluice gates and the turbines. The annual energy generation was found to be $596.04 \mathrm{GWh}$, some $24 \%$ increase in annual energy yield. This result indicates the advantage of ebb mode generation therefore the authors wished to optimise different parameters such as turbine size and start head to provide a 'best' option for the Swansea Bay tidal lagoon in terms of annual energy generated.

\subsection{Optimised Ebb Mode Generation Results}

In routines such as this, energy capture can be maximised by choosing a suitable delay before generation begins. The 365 day simulation was run for a series of starting heads, $S$, at $0.5 \mathrm{~m}$ intervals ranging from $0.5 \mathrm{~m}$ to $4 \mathrm{~m}$. At each starting head the annual energy was calculated, the results are plotted in Figure 11. From Figure 11 it is evident that delaying generation until a $3 \mathrm{~m}$ head results in the highest annual energy production, which was found to be $664.7 \mathrm{GWh}$. At larger starting heads the annual energy production reduces, the most likely reason for this effect is that if generation is postponed for too long there will only be a short generation window. Similarly, with a short delay 
only small heads will be seen across the lagoon resulting in lower flow rates and a reduced annual energy production.

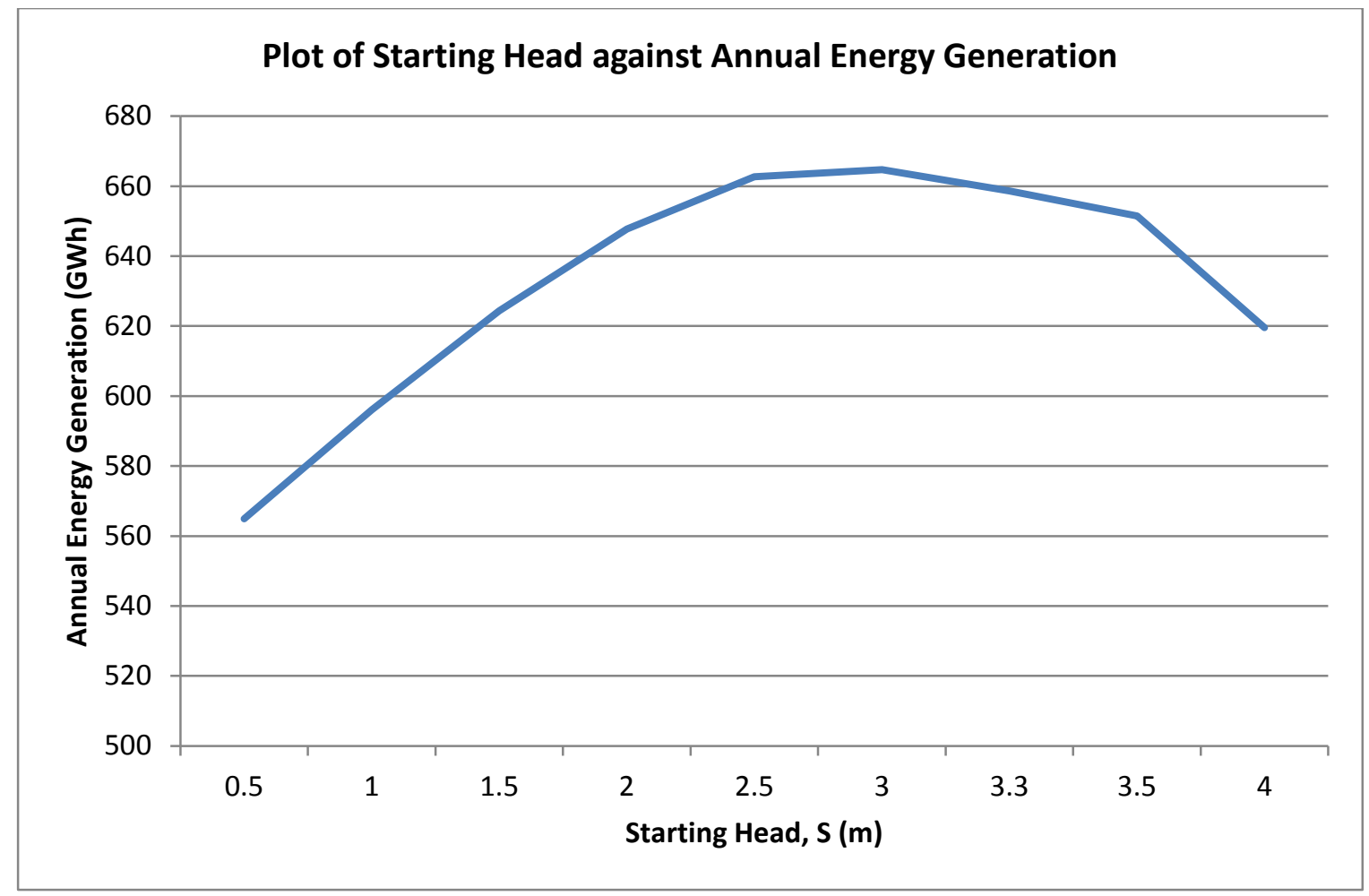

Figure 11: Graph showing the effect of changing starting head

A range of turbine diameters were entered into the model and the associated annual energy production was calculated accordingly. For each simulation 16 turbines were used and the starting head was defined as $3 \mathrm{~m}$, with the power limit for the plant restricted to $320 \mathrm{MW}$. The plot of diameter against energy is shown in Figure 12, what this plot shows is that up until $8 \mathrm{~m}$ an increase in the diameter results in an increase in the annual energy production. For turbine diameters greater than $8 \mathrm{~m}$, the result of a lower annual energy generation is likely due to the fact that the lagoon empties too quickly reducing the head significantly. For smaller diameters the opposite is true, the limited capacity of these turbines means much lower flow rates. The small percentage difference between the annual energy production of the $7 \mathrm{~m}$ and $8 \mathrm{~m}$ diameter turbine could indicate that the $7 \mathrm{~m}$ diameter turbine chosen by TLSB would be suitable; it also offers advantages from an economic point of view with reduced manufacturing and installation costs. 


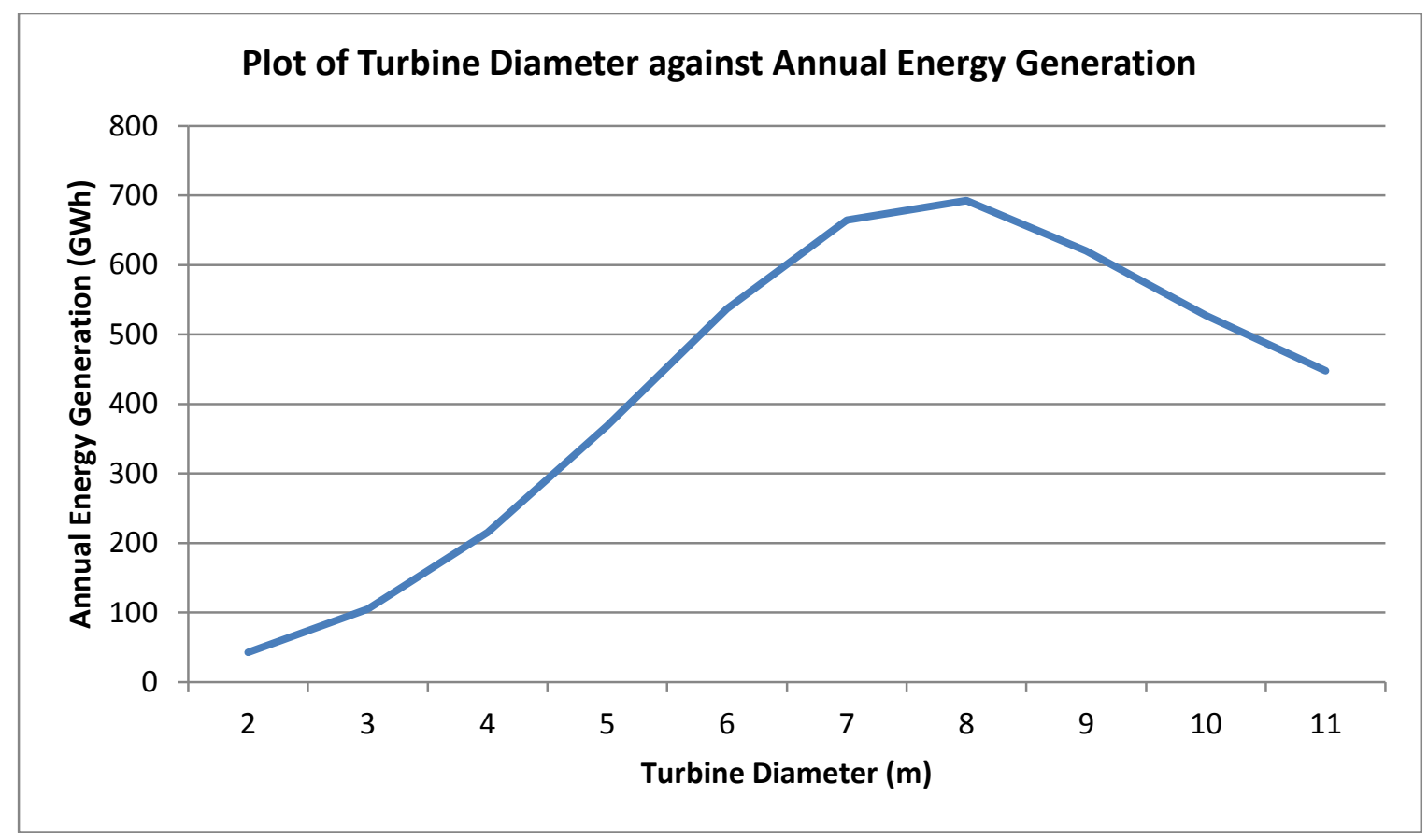

Figure 12: Graph showing the effect of changing turbine diameter

The effect of the changing the number of turbines has also been explored. Figure 13 shows that for 7 $\mathrm{m}$ diameter and $3 \mathrm{~m}$ starting head the annual energy production increases proportionately to the number of turbines until a point at which it no longer increases as the lagoon has reached a maximum fixed percentage of the potential energy of the site. Figure 13 would suggest that 25 turbines are optimal, however for a relatively small gain in annual energy there is a more significant increase in the associated cost of the additional turbines making this a less attractive arrangement.

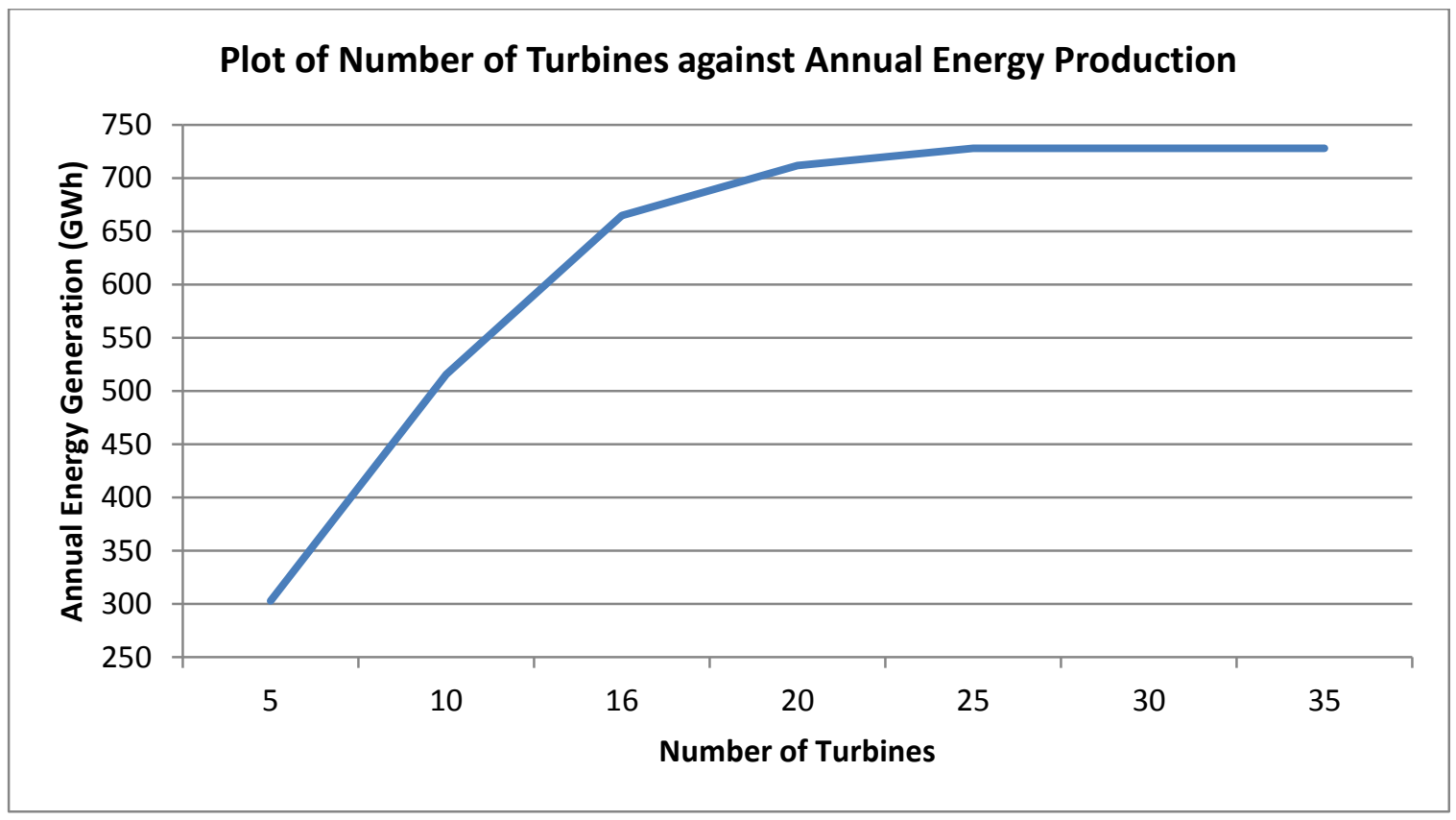

Figure 13: Graph showing the effect of changing the number of turbines 
In conclusion, using the optimisation curves, the data can be input into the simulation to give an estimate of the optimised tidal lagoon in Swansea Bay using ebb mode generation. It was found that using a $3 \mathrm{~m}$ starting head and twenty five $8 \mathrm{~m}$ diameter turbines, $726.8 \mathrm{GWh}$ of generated energy is possible, though a scheme with fewer smaller turbines would be advantageous to reduce the overall levelised cost of energy.

\subsubsection{Ebb Mode Generation with Flood Pumping}

Ebb mode generation with flood pumping at high tide has been shown in earlier studies to further enhance energy capture (Shaw \& Watson, 2003), therefore it will be considered in this study. Pumping begins as soon as the sluice gates have closed, when the levels in the basin and sea equalise. Water is then pumped from the sea into the lagoon to increase the head available for generation later in the tidal cycle. The use of flood pumping and the calculation of the gain in net energy yield is dependent on many variables. The first is the turbine characteristics when acting as a pump and the calculation for this phase uses the same maximum output curve from the hill chart, however with a reduced power output attributed to the reduction in efficiency as a result of the reversed direction of flow, this study has imposed a limit of $90 \%$ of operating efficiency of the turbine. The calculation in MatLab uses 16 turbines, $7 \mathrm{~m}$ in diameter with thirty sluice gates and a starting head of $3 \mathrm{~m}$. A pumping height of $1 \mathrm{~m}$ was chosen based on the parameters of similar studies (Aggidis \& Benzon, 2013). This study gave an annual energy generation of $731.7 \mathrm{GWh}$ an increase of $10.1 \%$ compared to ebb generation using the same parameters. In this study pumping occurred at every high tide, however depending on the generating optimisation methods chosen it could be limited to neap tides only for example to match the peak power outputs across the tidal cycle. This study has considered a single pumping height, $1 \mathrm{~m}$, which represents the duration of pumping post high tide, however other studies have shown the annual energy yield is sensitive to this parameter (Haws, Wilson, \& Gibson, 1990). This result shows the potential for significant gains available from using pumping in the Swansea Bay lagoon scheme and further studies would be required in order to obtain an optimum pairing of pumping height and minimum generating head (Table 2). 


\begin{tabular}{|c|c|c|c|}
\hline Operating Mode & Input Parameters & & $\begin{array}{l}\text { Annual Energy Generation } \\
\text { (GWh) }\end{array}$ \\
\hline \multirow{3}{*}{ Dual Mode } & Turbine Diameter & $7 \mathrm{~m}$ & \multirow{3}{*}{479.8} \\
\hline & Number of turbines & 16 & \\
\hline & Minimum generating head & $1 \mathrm{~m}$ & \\
\hline \multirow{3}{*}{ Ebb Mode } & Turbine Diameter & $7 \mathrm{~m}$ & \multirow{3}{*}{596.04} \\
\hline & Number of turbines & 16 & \\
\hline & Minimum generating head & $1 \mathrm{~m}$ & \\
\hline \multirow{3}{*}{ Optimised Ebb Mode } & Turbine Diameter & $8 \mathrm{~m}$ & \multirow{3}{*}{726.8} \\
\hline & Number of turbines & 25 & \\
\hline & Minimum generating head & $3 \mathrm{~m}$ & \\
\hline \multirow{4}{*}{$\begin{array}{c}\text { Optimised Ebb Mode with } \\
\text { pumping }\end{array}$} & Turbine Diameter & $7 \mathrm{~m}$ & \multirow{4}{*}{731.7} \\
\hline & Number of turbines & 16 & \\
\hline & Minimum generating head & $3 \mathrm{~m}$ & \\
\hline & Pumping head & $1 \mathrm{~m}$ & \\
\hline
\end{tabular}

Table 2: Annual Energy generation figures for different operating modes

\section{$4 \quad$ Conclusions}

The purpose of this paper was to demonstrate the methods in which OD modelling has been used to examine the potential energy generation of a tidal lagoon in Swansea Bay over a number of different operating modes. The key results obtained from this research show that for dual mode generation, the annual energy generation is very similar to the published predictions by TLSB.

The optimal lagoon model assumes that the turbine is operating along the maximum output curve at all times and that efficiency is a function of unit speed, this demonstrates the theoretical energy available for a given scheme. Current developments that could be transferred from the wind industry relating to the use of asynchronous generators, coupled with frequency conversion ability at multi-megawatt values, could ensure an improved annual energy generation by following the continuous variation of head and flow rates at the best efficiency point of the model curve (Shorrock, 2014), however this requires further investigation. In the OD ebb mode studies, different starting heads, turbine sizes, number of turbines have been investigated to give the optimised generation routine, however this study has not included the detailed hydraulic design of the turbine ducts and sluice gates, which would give rise to entry and exit head losses affecting the annual energy generation. Studies (Burrows, et al., 2009) of a similar nature have revealed that more advanced 2D modelling under predicts the energy generation capabilities compared to a OD model by some $10 \%$, highlighting the need for a more rigorous approach. In addition if the figures stated 
are to be considered realistic estimates of potential energy returns, further turbine modelling (turbulent flow, cavitation, and flow concentration), increased sluice capabilities, 3D hydrodynamic modelling and sedimentation studies of the lagoon need investigating to enhance the accuracy of future model predictions. The OD model is also sensitive to the time step used, in this case the model shows a time step of 0.1 hours generates $596.04 \mathrm{GWh}$ for ebb mode, however a time step of 0.05 hours generates $648.2 \mathrm{GWh}$ and 0.01 hours $652.03 \mathrm{GWh}$ some $10 \%$ greater than 0.1 hours. Though the original time step was deemed small enough to minimise the truncation error in future modelling it is anticipated that further studies of the effect of different time steps will be investigated. Thus, in the absence of any specific studies available on the public domain to provide a more accurate estimation for these values it would be feasible to assume a cumulative uncertainty range well beyond the $10 \%$ overestimation, perhaps double or triple that value. As a next step additional studies are required to take place in order to clarify further the exact range of these values and thus minimise the uncertainty error.

Overall, the results from comparisons in this study show that ebb mode can increase annual energy generation by around $24 \%$ compared to dual mode generation alone under similar operating conditions. However, despite the lower annual energy generation dual mode has been favoured by developers due to the reduced impact it has on the lagoon environment in comparison to ebb mode generation (Ahmadian, Falconer, \& Bockelmann-Evans, 2014), this is due to relatively small change in the mean water level during the dual mode cycle such that the degree of alteration of the inner lagoon environment remains comparatively unchanged (Yates, Walkington, Burrows, \& Wolf, 2013). To establish the actual environmental impact effect of the lagoon requires detailed research in order to understand the estuarine environment. In 2012 TLSB plc published an Environment Impact Assessment scoping document with the study areas and methodologies of the assessment, since then an Environmental Statement has been published as part of the planning application documentation in February 2014. The current lagoon design has been selected by TLSB as it provides the best solution with regard to energy generation, environmental impact and cost viability.

\section{Acknowledgements}

The authors would like to thank Lancaster University Renewable Energy Group, SeaZone Solutions Ltd for providing the bathymetric data and Dr Duncan Whyatt of Lancaster Environment Centre for 
his invaluable assistance with ArcGIS. A special thanks also to Andritz Hydro for supplying the turbine data used in this research.

\section{References}

Aggidis, G. A. (2010, October 19). Tidal Range Fluid Machinery Technology and Opportunities. International Symposium on Ocean Power Fluid Machinery. London: IMechE.

Aggidis, G. A., \& Benzon, D. S. (2013). Operational optimisation of a tidal barrage across the Mersey estuary using 0D modelling. Ocean Engineering, 66, 69-81.

Aggidis, G. A., \& Feather, 0. (2012). Tidal range turbines and generation on the Solway Firth. Renewable Energy, 43, 9-17.

Ahmadian, R., Falconer, R., \& Bockelmann-Evans, B. (2014). Comparison of hydroenvironmental impacts for ebb-only and two-way generation for a Severn Barrage. Computers and Geosciences, 71, 11-19.

Baker, C. (2006). Tidal Lagoon Power Generation Scheme in Swansea Bay. Deparment of Trade and Industry. London: HM Government.

Bourban, S., Liddiard, M., Durand, N., Cheeseman, S., \& Baldock, A. (2013). High Resolution Modelling of Tidal Resouces, Extraction and Interactions around the UK. Proceedings of the 1st Marine Energy Technology Symposium METS 13. Washington D.C.

Brammer, J., Falconer, R., Ellis, C., \& Ahmadian, R. (2014). Physical and numerical modelling of the Severn Barrage. Sci China Tech Sci, 57, 1471-1481.

Burrows, R., Walkington, I., Yates, N., Hedges, T., Chen, D., Li, M., ... Prandle, D. (2009). Tapping the Tidal Power Potential of the Eastern Irish Sea. Joule Centre project JIRP 106/03.

Case, M. (2014, June 11). Tidal Lagoon Swansea Bay. BHA Summer Forum. Cardiff: British Hydropower Association.

Department of Energy. (1989). The Potential for Tidal Energy from Small Estuaries. London: HM Government.

ESRI. (2013, May 20). ArcGIS Desktop 9.3 Help. Retrieved from http://webhelp.esri.com/arcgisdesktop/9.3/index.cfm?TopicName=About_TIN_ surfaces

Falconer, R. A., Xi, J. Q., Lin, B. A., \& Ahmadian, R. (2009). The Severn Barrage and other tidal energy option: Hydrodynamic and power output modelling. Sci China Ser ETech Sci, 52(11), 3413-3424.

Friends of the Earth Cymru. (2004). Briefing - A Severn Barrage or tidal lagoons? Hammons, T. J. (1993). Tidal Power. Proceedings of the Institute of Electrical and Electronic Engineers, 81(3), 419-433.

Haws, E. T., Wilson, E. A., \& Gibson, H. R. (1990). Pumped storage in the proposed Mersey tidal power project. Pumped Storage: Proceedings of the Conference Organized by the Institution of Civil Engineers, (pp. 295-312). London.

Hervouet, J. M. (2007). Hydrodynamics of Free Surface Flows. John Wiley and Sons.

Kilanehei, F., Naeeni, S. T., \& Namin, M. M. (2011). Coupling of 2DH-3D Hydrodynamic Model for Simulating Flow Around River Hydraulic Structures. World Applied Sciences Journal, 15(1), 63-77.

Krenn, J., Helmut, K., \& Sallaberger, M. (2013). Small and Mid-Size Pump-Turbines with Variable Speed. Energy and Power Engineering, 5, 48-54. 
Poyry Consultants. (2014). Levelised Cost of Power from Tidal Lagoons. Tidal Lagoon Swansea Bay plc.

Prandle, D. (1984). Simple Theory for Designing Tidal Power Schemes. Advanced Water Resource, 7(1), 21-27.

Randall, D. A. (2006). The Shallow Water Equations. Fort Collins: Colorado State University.

Schneeberger, M. (2010, October 19). SIHWA Tidal Power Plant Ready for Commissioning. International Symposium on Ocean Power Fluid Machinery. London: IMechE.

Sea Zone Solutions. (2013, May 20). Sea Zone Solutions. Retrieved from http://www.seazone.com/

Shaw, T. L., \& Watson, M. J. (2003). The effects of pumping on the energy potential of a tidal power barrage. Proceedings of the Institution of Civil Engineers Engineering Sustainability 156, 111-117.

Shorrock, M. (2014, December 03). Swansea Bay Tidal Lagoon: a blueprint for a new kind of energy infrastructure. IET Hunter Memorial Lecture 2014. Birmingham.

Sustainable Development Commission. (2007). Turning the Tide: Tidal Power in the UK. Sustainable Development Commission, London.

UKHO. (2013, May 20). United Kingdom Hydrographic Office. Retrieved from http://www.ukho.gov.uk/Pages/Home.aspx

VIMS. (2013, May 20). Tide Analysis: Building Blocks of the Tide. Retrieved from http://web.vims.edu/physical/research/TCTutorial/tideanalysis.htm

WS Atkins. (2004). Tidal Electric Limited Feasibility Study for a Tidal Lagoon in Swansea Bay. Retrieved May 26, 2013, from Tidal Electric Ltd: http://tidalelectric.com/resources-feasibility.shtml

Yates, N., Walkington, I., Burrows, R., \& Wolf, J. (2013). Appraising the extractable tidal energy resource of the UK's western coastal waters. Philosophical Transactions of the Royal Society, A 371(20120181). 